\title{
Preclinical to clinical translation of anti-PD-1 blockade
}

\author{
Heather Hirsch ${ }^{1 *}$, Elaine Pinheiro ${ }^{1}$, Mark Ayers ${ }^{2}$, Jared Lunceford ${ }^{2}$, Michael Nebozhyn $^{3}$, Erin Murphy ${ }^{4}$, Mingmei Cai ${ }^{1}$, \\ Yanhong $\mathrm{Ma}^{1}$, Manjiri Sathe ${ }^{4}$, Terri McClanahan ${ }^{2}$ \\ From 30th Annual Meeting and Associated Programs of the Society for Immunotherapy of Cancer (SITC 2015) \\ National Harbor, MD, USA. 4-8 November 2015
}

\section{Background}

Pembrolizumab (MK-3475), a humanized monoclonal IgG4 antibody against programmed death receptor 1 (PD-1), is currently being studied in clinical trials across more than 30 types of cancers. Immunotherapy with anti-PD-1 monoclonal antibodies such as pembrolizumab shows robust, durable anti-tumor activity in multiple indications including patients with advanced melanoma. A more complete understanding of the mechanism of action and biology associated with both response and resistance to pembrolizumab is critical to better inform on future clinical development and will also provide insight into the development of additional immuno-oncology therapies.

\section{Methods and results}

To further support the clinical development of pembrolizumab, muDX400 (an anti-PD1 murine surrorgate) was tested in syngeneic mouse models. Response to muDX400 treatment in several syngeneic tumor models was broadly classified into 3 categories: highly responsive, partially responsive, and intrinsically resistant to therapy. Using a multifaceted approach, tumors from these models were extensively characterized at the molecular and cellular level by gene expression profiling and whole exome sequencing to help elucidate mechanisms of action and biology associated with response and resistance to antiPD1 treatment.

These findings are also being compared to data that we are obtaining from ongoing clinical trials with pembrolizumab to help better understand the translatability of these preclinical models to the clinic. For example, both the IFN- $\gamma$ and the expanded-immune signatures showed statistically significant associations with ORR and PFS in Keynote 001 Phase Ib melanoma trial. Analysis of topranked genes on the platform led to the discovery of two new signatures, "TCR-signaling" and "De novo" that were enriched in T cell markers and MHC Class I and II genes. Measuring immune-related biomarkers, including $\mathrm{T}$ cell specific, antigen presentation-related, and IFN- $\gamma$ signaling-related genes, may allow for improved selection of patients likely to respond to anti-PD-1 therapy with pembrolizumab.

The translatability of molecular features such as gene expression and mutation burden will be assessed in syngeneic mouse models.

\section{Conclusions}

These preclinical syngeneic tumor models allow us the opportunity to formulate and test specific hypotheses to more completely understand the biology behind the clinical successes currently observed with the novel cancer immunotherapies including anti-PD-1 antibodies such as pembrolizumab.

\section{Authors' details}

'Merck Research Laboratories, Boston, MA, USA. ${ }^{2}$ Merck \& Co., Inc., Kenilworth, NJ, USA. ${ }^{3}$ Merck MRL, Lansdale, PA, USA. ${ }^{4}$ Merck \& Co., Inc., Palo Alto, CA, USA.

Published: 4 November 2015

doi:10.1186/2051-1426-3-S2-P92

Cite this article as: Hirsch et al:: Preclinical to clinical translation of antiPD-1 blockade. Journal for ImmunoTherapy of Cancer 2015 3(Suppl 2):P92.

${ }^{1}$ Merck Research Laboratories, Boston, MA, USA

Full list of author information is available at the end of the article

(c) 2015 Hirsch et al. This is an Open Access article distributed under the terms of the Creative Commons Attribution License (http:// creativecommons.org/licenses/by/4.0), which permits unrestricted use, distribution, and reproduction in any medium, provided the original work is properly cited. The Creative Commons Public Domain Dedication waiver (http://creativecommons.org/publicdomain/ zero/1.0/) applies to the data made available in this article, unless otherwise stated. 